Hydrology and Earth System Sciences, 8(1), 47-61 (2004) C EGU

\title{
Spatial and temporal variations in precipitation in the Upper Indus Basin, global teleconnections and hydrological implications
}

\author{
David R. Archer ${ }^{1}$ and Hayley J. Fowler ${ }^{2}$ \\ ${ }^{1}$ JBAConsulting, South Barn, Broughton Hall, Skipton, North Yorkshire, BD23 3AE, UK \\ ${ }^{2}$ Water Resource Systems Research Laboratory, School of Civil Engineering and Geosciences, University of Newcastle, Newcastle upon Tyne NE1 7RU, UK \\ Email for corresponding author: davearcher@yahoo.com
}

\begin{abstract}
Most of the flow in the River Indus from its upper mountain basin is derived from melting snow and glaciers. Climatic variability and change of both precipitation and energy inputs will, therefore, affect rural livelihoods at both a local and a regional scale through effects on summer runoff in the River Indus. Spatial variation in precipitation has been investigated by correlation and regression analysis of long-period records. There is a strong positive correlation between winter precipitation at stations over the entire region, so that, for practical forecasting of summer runoff in some basins, a single valley-floor precipitation station can be used. In contrast, spatial relationships in seasonal precipitation are weaker in summer and sometimes significantly negative between stations north and south of the Himalayan divide. Although analysis of long datasets of precipitation from 1895 shows no significant trend, from 1961-1999 there are statistically significant increases in winter, in summer and in the annual precipitation at several stations. Preliminary analysis has identified a significant positive correlation between the winter North Atlantic Oscillation index (NAO) and winter precipitation in the Karakoram and a negative correlation between a monthly NAO index and summer rainfall at some stations.
\end{abstract}

Keywords: upper Indus basin, climate change, time series analysis, spatial correlation, teleconnections

\section{Introduction}

The economic life of Pakistan depends to a considerable extent on the flow of the River Indus which supports large areas of irrigated agriculture and a significant proportion of the installed power capacity of the country. More than $80 \%$ of the flow in the Indus as it emerges onto the Punjab plains is derived from seasonal and permanent snowfields and glaciers. Direct runoff from monsoon rainfall, mainly from the southern foothills, also makes a contribution, the proportion of which increases progressively eastward on the neighbouring Indus tributaries of Jhelum, Chenab, Ravi and Sutlej, as well as on the upper Ganges in Indian and Nepalese Himalaya. Monsoon precipitation as snow at high elevations in the eastern Himalayas also affects glacier mass balance and, ultimately, the hydrological regime.

De Scally (1994) showed that summer runoff in the Kunhar River, a south-flowing tributary of the Jhelum, was significantly correlated with the preceding winter snowpack. Archer (2003) obtained correlation coefficients greater than
0.7 between preceding winter precipitation (largely measured as rain at valley stations) and summer runoff in southern mountain tributaries. In addition, summer runoff in high elevation northern catchments such as the Hunza and Shyok, is equally strongly correlated with summer temperatures measured at valley locations (Archer, in press).

While such relationships suggest the possibility of improved seasonal flow forecasting and water resources management on the Indus, they also demonstrate the vulnerability of Indus runoff to short term fluctuations as well as to long term climate change. Valleys of the upper Indus basin (UIB) and tributaries receive little precipitation (annual totals typically less than $150 \mathrm{~mm}$ ) and inhabitants depend on irrigated agriculture fed by water from snow and glacier melt. The annual variability of temperature and precipitation influences, strongly, the viability and productivity of agriculture. Climatic variability and change will, therefore, have a significant impact on rural livelihoods at both a local and a regional scale. 
Global climatic change studies have been focused on temperature, the recent upward trends in which can be ascribed with reasonable confidence to anthropogenic influences (IPCC, 2001). Trends have also been identified in precipitation amounts, with notable increases over middle and high latitudes of the Northern Hemisphere. However, research on climate change in the Himalayas has been concentrated on the behaviour of glaciers in the Greater Himalaya (Hasnain, 1999) and the relationship between teleconnections such as the El Niño Southern Oscillation and winter and monsoonal rainfall. Little attention has been paid to climate change in the trans-Himalayan region of the Hindu Kush and Karakoram Mountains (Fig. 1).

Glaciers in the Greater Himalaya are reported to be diminishing rapidly (Mastny, 2000; Pearce, 2002); indeed, most of the world's mountain glaciers have been shrinking for at least the last thirty years (WGMS, 2000). Shrinking glaciers can be accompanied by glacially-dammed lakes and increased flood risks from glacial lake outbursts. Yamada and Sharma (1992) note 13 glacial lake outburst floods in Nepal since 1960. In contrast, Hewitt (1998) reports widespread glacier expansion of larger glaciers in the Central Karakoram, accompanied by an exceptional number of reported glacier surges. There is a continuing risk in the Karakoram Mountains from glacial outburst floods generated by surging tributary glaciers blocking main unglaciated valleys, such as have caused extreme floods in the past (Hewitt, 1982; Archer, 2002). This contrast in the behaviour of glaciers suggests a pattern of climatic change in the Karakoram and Hindu Kush different from that in the Himalayas.

It is of considerable practical interest in terms of both water resources and flooding to establish patterns of climatic variability and change and their linkage to glacial behaviour. Trends in precipitation in the Greater Himalaya have been studied by many authors. Shrestha et al. (2000) found no distinct long term trends in precipitation (mainly of monsoon origin) from 1948 to 1994 in the Nepalese Himalayas although the regional series showed significant variability at annual and decadal time scales. However, further west in the Himalayan foothills, Borgaonkar et al. (1996) found significantly decreasing trends in both winter and summer precipitation in a record at Shimla from 1876 to 1982, whilst Singh and Sen Roy (2002) observed a slight upward trend in winter rainfall and a slight downward trend in monsoon rainfall between 1964 and 1992 in the Beas catchment.

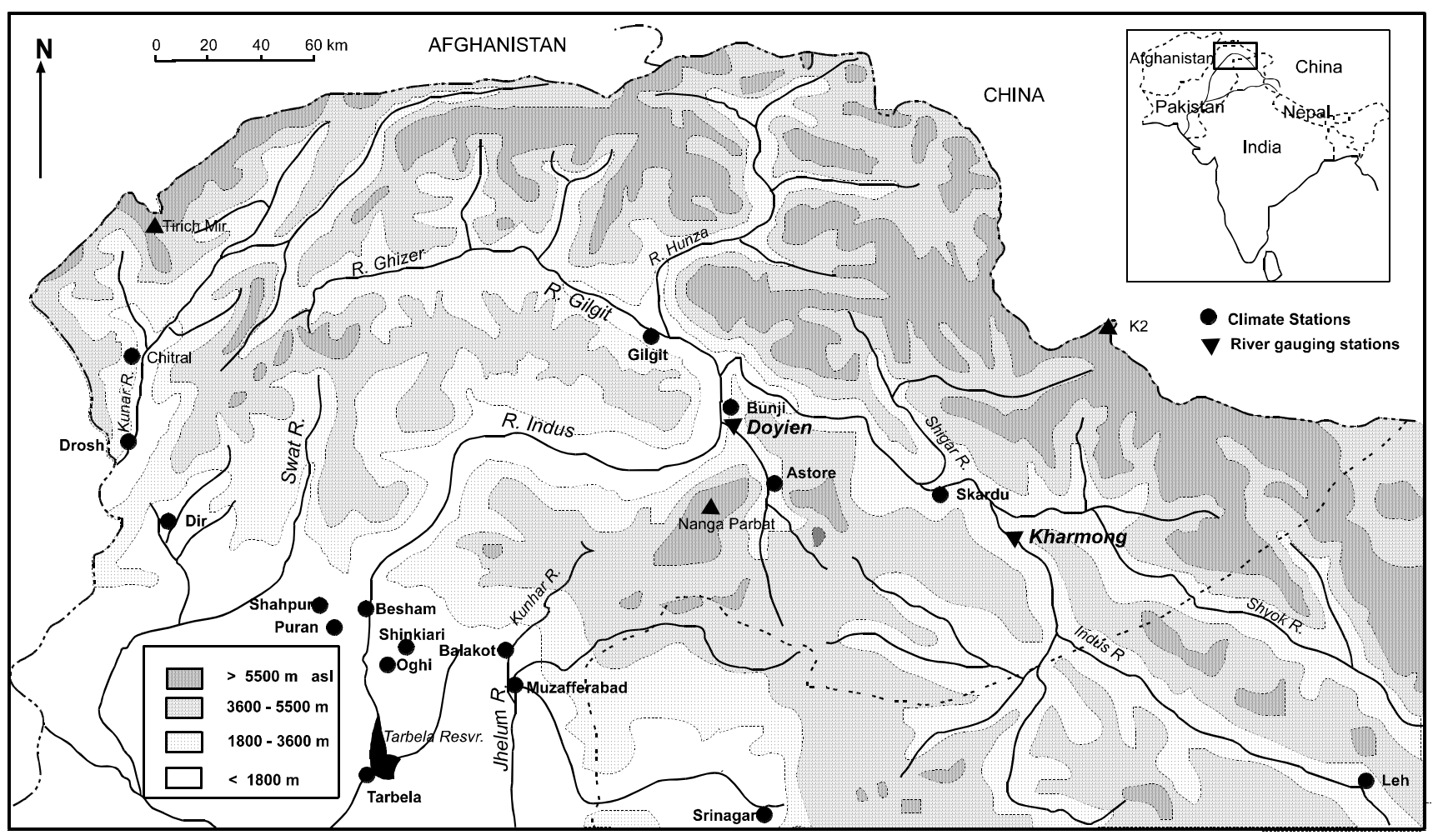

Fig.1. The upper Indus Basin showing the location of climate and streamflow records used in analysis. Inset shows continental location of study area. 
Climatic controls in the UIB are quite different from the eastern or Greater Himalaya. Over the UIB, most of the annual precipitation falls in winter and spring, predominantly influenced by weather systems from the west. Incursions of the monsoon bring occasional rain but, even during summer months, not all precipitation derives from monsoon sources (Wake, 1987). In the Karakoram, Miehe (1992) reports a general perception that winter precipitation has decreased over the last 30 to 40 years, a view supported by changes in vegetation and a change in the duration of winter closure of high mountain passes. A decomposition of annual series of monthly precipitation into trend, cyclical, autoregressive and random components in the UIB by Khan (2001) identified no components compatible with climate change. However, separate consideration of seasonal statistics can reveal patterns of change not evident using the decomposition method.

With respect to teleconnections, the Asian monsoon is one of the most important components in the coupled oceanland-atmosphere system and significant links have been identified between Indian monsoon rainfall (IMR) and a wide range of large scale features of the global climate, including El Niño Southern Oscillation (ENSO) (Yang, 1996) and Mediterranean pressure indices (Raicich et al., 2003). Of particular interest is the inverse relationship between IMR and precursory Eurasian winter snow cover (EWSC), first identified by Hahn and Shukla (1976) and subsequently developed in numerous studies (Ye and Bao, 2001). Analysis of long duration trans-Himalayan climate series could conceivably provide a missing link to these imperfectly understood eastern and western teleconnections. No previous work has been done on teleconnections with climate in the upper Indus basin and very little regionally on the winter precipitation that is the key to water resources management.

This study investigates the trends and fluctuations in seasonal rainfall series in the UIB over more than 100 years; temperature time series are investigated similarly in concurrent research. A preliminary study has been made of external factors, demonstrated by teleconnections, which influence the climate of the area and which may themselves be subject to climatic variability or change, anthropogenic or otherwise.

\section{Data}

Several data sources have been used for this analysis and measurement locations are shown in Fig. 1 and listed in Table 1.

1. The Pakistan Meteorological Department (PMD) maintains standard meteorological stations ranging in elevation from 980 metres above sea level at Balakot to $2394 \mathrm{~m}$ at Astore. Daily records of precipitation are available for Gilgit and Skardu, whilst monthly records are available at the remainder.

2. For the pre-partition period, a full record of daily precipitation for Gilgit and Skardu for the period 1893 to 1947 was extracted from reports of the India Meteorological Dept. (IMD) held at the UK Meteorological Office.

3. Monthly precipitation records for Srinagar (1893-1999) and Leh (1882-1968) in Indian-controlled Kashmir were obtained from the Climate Research Unit at University of East Anglia, England. The record for Leh is intermittent during the decade before closure.

4. The Pakistan Water and Power Development Authority (WAPDA) maintains a network of climatological stations, some of which have operated for more than 30 years. The stations are concentrated in the southern part of the region.

The 17 stations are listed in Table 1 and cover a distance from east to west of about $300 \mathrm{~km}$ and from north to south of over $200 \mathrm{~km}$. Leh is a further $200 \mathrm{~km}$ to the east.

\section{DATA VALIDATION}

Reliability and interpretation of data depend on their accuracy and consistency; it is particularly important to distinguish trend and step changes in rainfall arising from changes in station location or practice from those resulting from climate change. Validation checks were carried out on the records to identify inconsistencies.

The records are thought to be consistent with respect to measurement practice. Standard meteorological measurement practice was established by the IMD in 1891 and the same standards have been adopted for rainfall by PMD and WAPDA.

Site changes have occurred for the two long records at Gilgit and Skardu. The original stations were situated at the British administrative headquarters but were moved to their present airport sites after 1947. In the case of Gilgit, the move was a distance of $1.5 \mathrm{~km}$ and, at Skardu, a distance of $8 \mathrm{~km}$; in each case, the station remained at nearly the same elevation on the valley floor. In spite of the limited changes, discontinuities in the rainfall records coincide with the change of sites and require treatment as separate records.

\section{Environmental conditions in the UIB}

The region to be investigated stretches from the Hindu Kush 
Table 1. Climate stations used for analysis

\begin{tabular}{|c|c|c|c|c|c|}
\hline No. & Station & Elevation $m A O D$ & Record Period & Interval & Agency or Source \\
\hline 1 & Chitral & 1499 & $1965-91$ & $\mathrm{D}$ & 1 \\
\hline 2 & Drosh & 1465 & $1931-97$ & M & 1 \\
\hline 3 & Gilgit & 1460 & 1894-99 & $\mathrm{D}$ & 1,2 \\
\hline 4 & Bunji & 1372 & $1952-97$ & M & 1 \\
\hline 5 & Astore & 2394 & 1954-97 & M & 1 \\
\hline 6 & Skardu & 2210 & 1894-99 & $\mathrm{D}$ & 1,2 \\
\hline 7 & Srinagar & 1587 & 1893-99 & M & 3 \\
\hline 8 & Leh & 3506 & $1882-68$ & M & 3 \\
\hline 9 & Dir & 1425 & $1967-97$ & M & 1 \\
\hline 10 & Shahpur & 2012 & $1963-96$ & $\mathrm{D}$ & 4 \\
\hline 11 & Puran & 1067 & $1963-96$ & $\mathrm{D}$ & 4 \\
\hline 12 & Besham & 480 & $1970-97$ & $\mathrm{D}$ & 4 \\
\hline 13 & Oghi & 1128 & $1961-96$ & $\mathrm{D}$ & 4 \\
\hline 14 & Shinkiari & 991 & $1961-96$ & $\mathrm{D}$ & 4 \\
\hline 15 & Balakot & 980 & $1961-90$ & $\mathrm{D}$ & 4 \\
\hline 16 & Muzafferabad & 686 & $1962-89$ & $\mathrm{D}$ & 4 \\
\hline 17 & Tarbela & 610 & 1960-99 & M & 4 \\
\hline \multicolumn{2}{|c|}{ Interval: } & $\mathrm{D}=$ Daily & $\mathrm{M}=$ Monthly & & \\
\hline \multicolumn{2}{|c|}{ Agency: } & $1=\mathrm{PMD}$ & 2. IMD & $3=\mathrm{CRU}$ & $4=$ WAPDA \\
\hline
\end{tabular}

Table 2. Seasonal total and percentage precipitation

\begin{tabular}{lllllllll}
\hline No. & Station & Year & $\begin{array}{l}\text { Jan-Mar } \\
m m\end{array}$ & $\begin{array}{l}\text { Apr-Jun } \\
m m\end{array}$ & $\begin{array}{l}\text { Jul-Sep } \\
m m\end{array}$ & $\begin{array}{l}\text { Oct-Dec } \\
m m\end{array}$ & $\begin{array}{l}\text { Oct-Mar } \\
\text { \% } \begin{array}{l}\text { of year } \\
\text { \% of year }\end{array}\end{array}$ \\
\hline 1 & Chitral & 441.7 & 226.1 & 113.9 & 23.3 & 78.4 & 68.9 & 31.1 \\
2 & Drosh & 636.8 & 257.6 & 205.5 & 70.2 & 103.5 & 56.7 & 43.3 \\
3 & Gilgit & 131.2 & 25.6 & 54.5 & 37.4 & 13.7 & 30.0 & 70.0 \\
4 & Bunji & 126.3 & 29.9 & 58.7 & 45.5 & 18.0 & 37.9 & 62.1 \\
5 & Astore & 516.7 & 180.7 & 189.1 & 72.0 & 74.9 & 49.5 & 50.5 \\
6 & Skardu & 222.3 & 94.0 & 65.2 & 32.8 & 30.3 & 55.9 & 44.1 \\
7 & Srinagar & 683.0 & 240.3 & 192.7 & 159.4 & 90.6 & 48.4 & 51.6 \\
8 & Leh & 92.7 & 27.3 & 16.8 & 37.5 & 11.1 & 41.4 & 58.6 \\
9 & Dir & 1446.4 & 540.4 & 328.3 & 383.2 & 194.5 & 50.8 & 49.2 \\
10 & Shahpur & 1429.6 & 447.9 & 320.4 & 479.5 & 181.8 & 44.0 & 56.0 \\
11 & Puran & 1281.8 & 381.7 & 274.5 & 461.2 & 164.4 & 42.7 & 57.4 \\
12 & Besham & 1098.8 & 397.0 & 250.1 & 311.3 & 140.4 & 48.9 & 51.1 \\
13 & Oghi & 1178.9 & 383.0 & 236.4 & 398.0 & 161.5 & 46.2 & 53.8 \\
14 & Shinkiari & 1341.9 & 324.7 & 236.2 & 639.9 & 141.1 & 34.7 & 65.3 \\
15 & Balakot & 1731.0 & 454.7 & 318.4 & 788.5 & 169.4 & 36.1 & 63.9 \\
16 & Muzafferabad & 1367.2 & 338.1 & 274.3 & 615.6 & 139.2 & 34.9 & 65.1 \\
17 & Tarbela & 903.0 & 204.4 & 134.6 & 478.0 & 86.0 & 32.2 & 67.8 \\
\hline
\end{tabular}

range on the borders of Afghanistan through the Karakoram Range to the western margins of the Tibetan plateau (Fig. 1). The main area of interest lies to the north of the Himalayas but stations further south have been included for comparison.
The region is predominantly in the North West Frontier Province and Northern Areas of Pakistan but includes the neighbouring part of Indian-controlled Kashmir. It is bordered on the north by China. It is a high mountain region 
with many peaks exceeding 7000 metres and contains the greatest area $\left(\sim 22000 \mathrm{~km}^{2}\right)$ of perennial snow and ice outside the polar regions; in winter, the area of snow cover can be an order of magnitude greater (Hewitt, 2001). There are several thousand individual glaciers and more than twenty exceed $25 \mathrm{~km}$ in length.

In winter and spring, the region is frequently under the influence of the Tibetan anticyclone but it is also affected by westerly waves originating primarily from the Mediterranean or the Caspian Sea (Singh et al., 1995). During their passage from Afghanistan, winds up to $500 \mathrm{Mb}$ generally become southerly and south westerly, resulting in an accentuation of weather systems or the creation of a secondary low pressure area over Pakistan (Shaukat Ali Awan, pers. comm.). Moist air is drawn in from the Arabian Sea and, in spite of the tracking route of depressions, winter precipitation decreases sharply northward. The monsoon makes brief and infrequent incursions between July and September but the amount of precipitation it brings diminishes rapidly from the south-east to the north-west. Seasonal amounts and percentages for selected stations are shown in Table 2.

Table 2 illustrates a remarkable variation in yearly and seasonal precipitation totals and their distribution. The valleys of the UIB and major tributaries have very low annual totals but the season of maximum rainfall varies from the first quarter at Chitral, Drosh and Skardu, to the second at Gilgit, Bunji and Astore and the third at Leh. Annual totals increase southward but, as shown by Chitral, Drosh and Astore on the northern side of the Himalayan divide, the increase is mainly in winter and spring precipitation. Summer totals remain low and are little influenced by monsoon rainfall. Whilst Srinagar, in the Jhelum catchment, lies south of the Great Himalaya, it is shielded from the monsoon by the Pir Panjal Range and its regime has more in common with northern stations than with stations further west that catch the full effect of the monsoon.

Across the divide, at climate stations in southwardoriented valleys, annual rainfall totals have increased sharply mainly because of the rapid growth in the summer monsoon (July to September) rainfall. However, precipitation in other seasons also increases and, except for Tarbela (53\%), the summer percentage is less than half the annual total.

Climatic variables are strongly influenced by altitude. Northern valley floors are arid, with annual precipitation of 100 to $200 \mathrm{~mm}$. However, in tributary valleys of the Gilgit River, precipitation increases with elevation to over $600 \mathrm{~mm}$ at $4400 \mathrm{~m}$, (Cramer, 1993; Jacobsen, 1993), while glaciological studies suggest accumulation rates of 1500 to $2000 \mathrm{~mm}$ at $5500 \mathrm{~m}$ (Wake 1989).

\section{Regional correlation of precipitation time series}

Mountain climates show both spatial and altitudinal variability and mountainous regions are said to require a much greater density of precipitation stations than neighbouring flat lands to achieve the same reliability of areal estimates. The existing network falls short, by more than an order of magnitude, of the minimum requirement recommended by WMO (1970). Furthermore, it is biased by the predominant location of stations in valley floors. Given the mountain barriers between neighbouring stations and the spatial variation in annual and seasonal totals and distribution shown in Table 2, the prospect for establishing broad regional patterns of precipitation appears unpromising.

The extent to which individual stations or groups of stations are representative of the region in which they are located must therefore be established. Correlation matrices, drawn up between stations, are presented for the summer and winter half years in Table 3; they include stations both north (1 to 8 ) and south (9 to 17) of the main Himalayan divide.

With respect to the winter half year (October to March), there is a remarkable positive correlation of totals across the region both north and south of the divide. Significant correlations $(p<0.001)$ are obtained between stations west to east from Drosh to Srinagar. The highest correlations are for stations such as Astore, Srinagar and Drosh that receive higher annual precipitation than typical valley floor stations in the UIB (less than $200 \mathrm{~mm}$ ). Yet, Gilgit is also correlated significantly across the region although at a lower level. Only Leh, with its unusually low winter average, fails to reach significant levels of correlation with other northern stations.

The regional correlation structure is quite different during the spring and summer half year (April to September). Positive and significant correlations, obtained for stations north of the divide, are strong only for neighbouring stations. There is a consistent weak but occasionally significant negative correlation (highlighted in Table 3) between stations north and south of the divide. This negative correlation is strongest between northern stations and Tarbela that receives the highest proportion of its annual precipitation during the summer monsoon. However, weak or negative correlations between northern and southern stations are not restricted to the monsoon period from July to September but may occur, also, during the spring quarter from April to June. A similar inverse relationship has been found between rainfall in central Tibet in July and August and Indian Summer Monsoon Rainfall (ISMR) (Chang, 
Table 3. Seasonal rainfall correlation between stations in the upper Indus basin A. (Upper triangle) October to March B. (Lower triangle) April to September

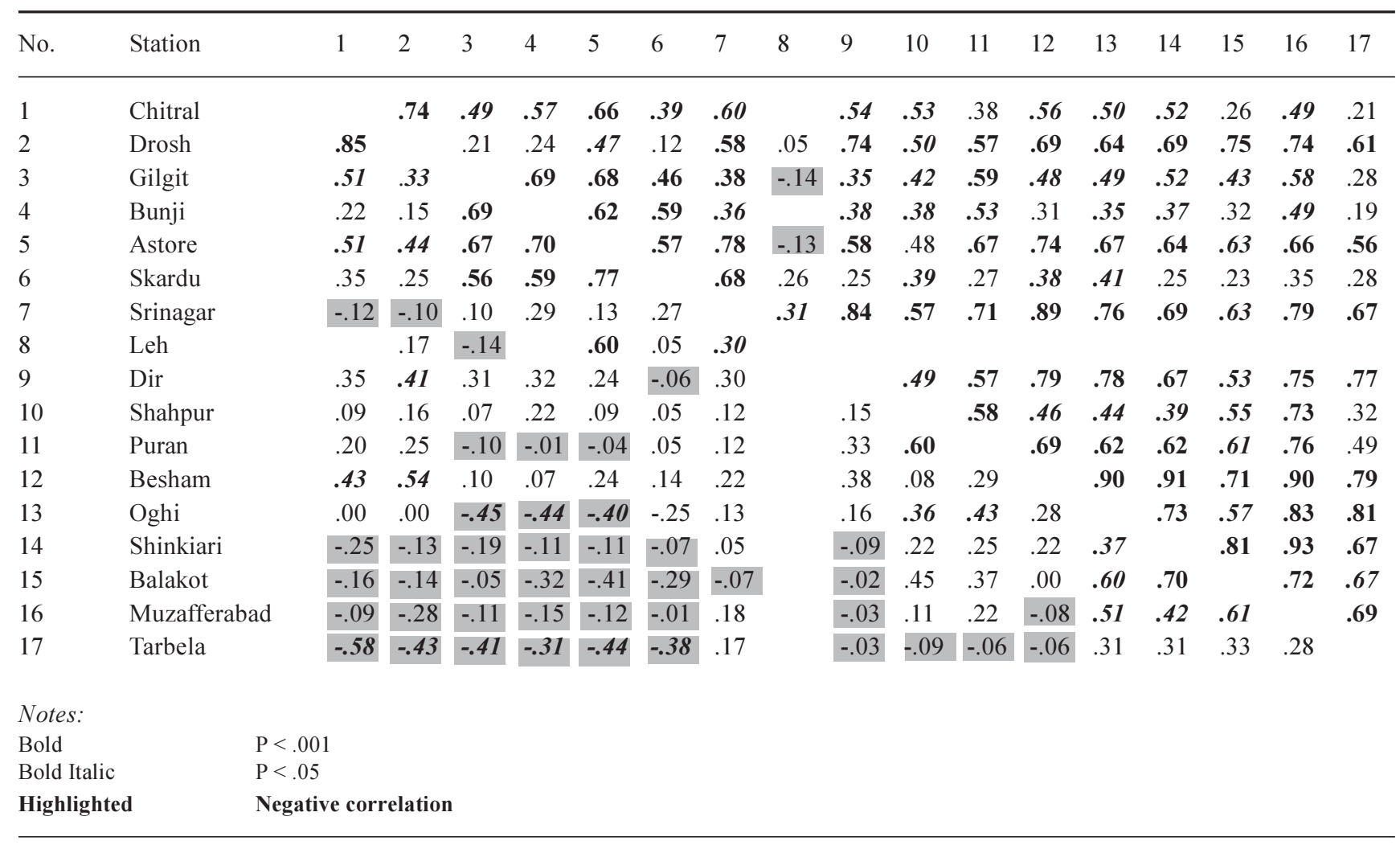

1981), though only for a limited time period.

Correlation analysis provides a framework in which the time series analysis can be viewed. The broadly correlated winter precipitation suggests that there may be a consistent regional pattern of time series change over an area which includes stations north and south of the Himalayan divide and incorporates stations situated on valley floors. In contrast, for the summer half year, the weaker spatial correlation suggests a consistent pattern of change only for northern stations, with diverse and possibly opposing patterns elsewhere. Consistent annual patterns may also be expected for northern stations but the poor spatial correlation of stations south of the divide in summer, when a high proportion of the annual precipitation occurs, may limit the generality of annual time series changes.

\section{Time Series analysis: regional trends}

Particular attention was paid to the long records from Skardu, Gilgit and Srinagar. To discover whether there was an overall regional signal during the period 1894-1999, they were analysed, annually and in three- and six-month seasonal periods, by fitting a linear least squares trend line to the annual deviation from the mean. In the case of Gilgit and Skardu, the record was split into pre- and post-partition periods (1894-1947 and 1954-1999 respectively), to reflect the discontinuity of location of the record. To detect trends over shorter time periods, the cumulative departure from the mean (CDM) was also calculated using the following formula:

$$
\mathrm{CDM}=\sum_{i=1}^{n}\left(x_{i}-\bar{x}\right) / \bar{x}
$$

For the period 1894-1999, there are no overall trends in annual rainfall (Fig. 2) at Srinagar, whilst at Gilgit and Skardu there is some evidence, not statistically significant, of an upward trend in annual rainfall only since 1960. Seasonal trends are shown in Fig. 3, winter (Oct-Mar), and Fig. 4, spring (Apr-Jun). Winter rainfall increases slightly at all three stations during the pre-partition period and, at Skardu, a strong upward trend continues into the 1990s. This trend is statistically significant $(\mathrm{p}<0.05)$ and contributes to an increase of $22 \mathrm{~mm}$ per decade since the 1960s. Spring rainfall shows no obvious overall pattern from 1894-1999 (Fig. 4) and, although all three stations show an overall increasing trend in summer rainfall (Fig. 5), the cumulative deviation curve shows little in common between the series.

The analysis was repeated using additional records from Astore, Bunji, Dir, Drosh, Puran, Shahpur and Shinkiari to 

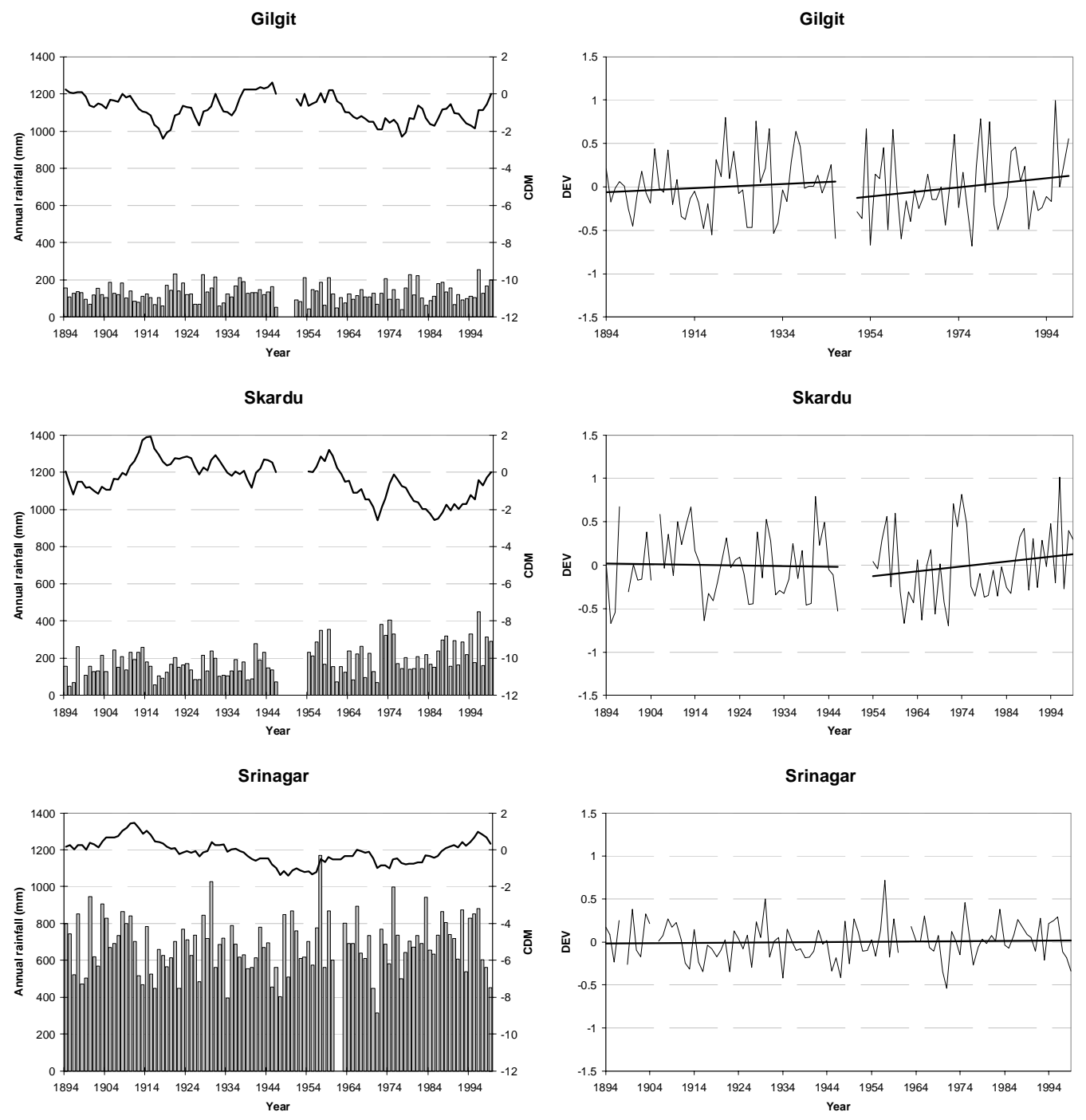

Fig.2. Trends in annual rainfall from 1894-1999. Left hand panels show annual rainfall series (bars-left axis) with the cumulative departure from the mean plotted as a line (right axis). Right hand panels show the deviation from the mean annual rainfall, with a least-squares fitted estimate of trend.

explore, in more detail, spatial trends during the period 19611999. The results of the analysis of seasonal trend are summarised in Table 4 to illustrate common patterns and regional differences. Increases $(+)$ and decreases $(-)$ are shown in Table 4 as a percentage of the period average (Table 2). At most stations, annual rainfall increases from 1961 to 1999 and the statistical significance of these increases in annual rainfall at Bunji is $(\mathrm{p}<0.10)$, at Gilgit, and Skardu, $(\mathrm{p}<0.05)$ and at Dir and Shahpur, $(\mathrm{p}<0.01)$.

Figure 6 shows the trend in winter (Oct-Mar) rainfall from 1961 to 1999 for ten stations, all of which show an increasing trend in winter rainfall over the period. At Skardu, Shahpur and Dir, this trend is statistically significant $(\mathrm{p}<0.05)$ (Table 4 ), with decadal increases in the order of 22, 103 and $120 \mathrm{~mm}$ respectively. At the northern stations of Skardu, Astore, Bunji and Gilgit, a slight decline in winter rainfall from 1961 to 1980 is offset by a large increase since the mid-1980s. A similar trend is seen in data from the southeasterly stations of Puran, Shinkiari and Shahpur, with recent increases since around 1990. However, at the south-westerly stations of Dir and Drosh, the reverse is true and an overall increase in winter rainfall from 1960-90 declined slightly thereafter.

Division of the winter (October-March) record into threemonthly periods shows that each contributes to the overall rise. January-March shows an increasing trend at nine of the ten stations with four of the increases being significant at the 0.05 level. Except for Skardu, statistically significant increases are in the south of the region. Whilst the October -December period shows the largest seasonal percentage increases, these are not significant statistically because the rainfall totals are smallest and most variable. More detailed 

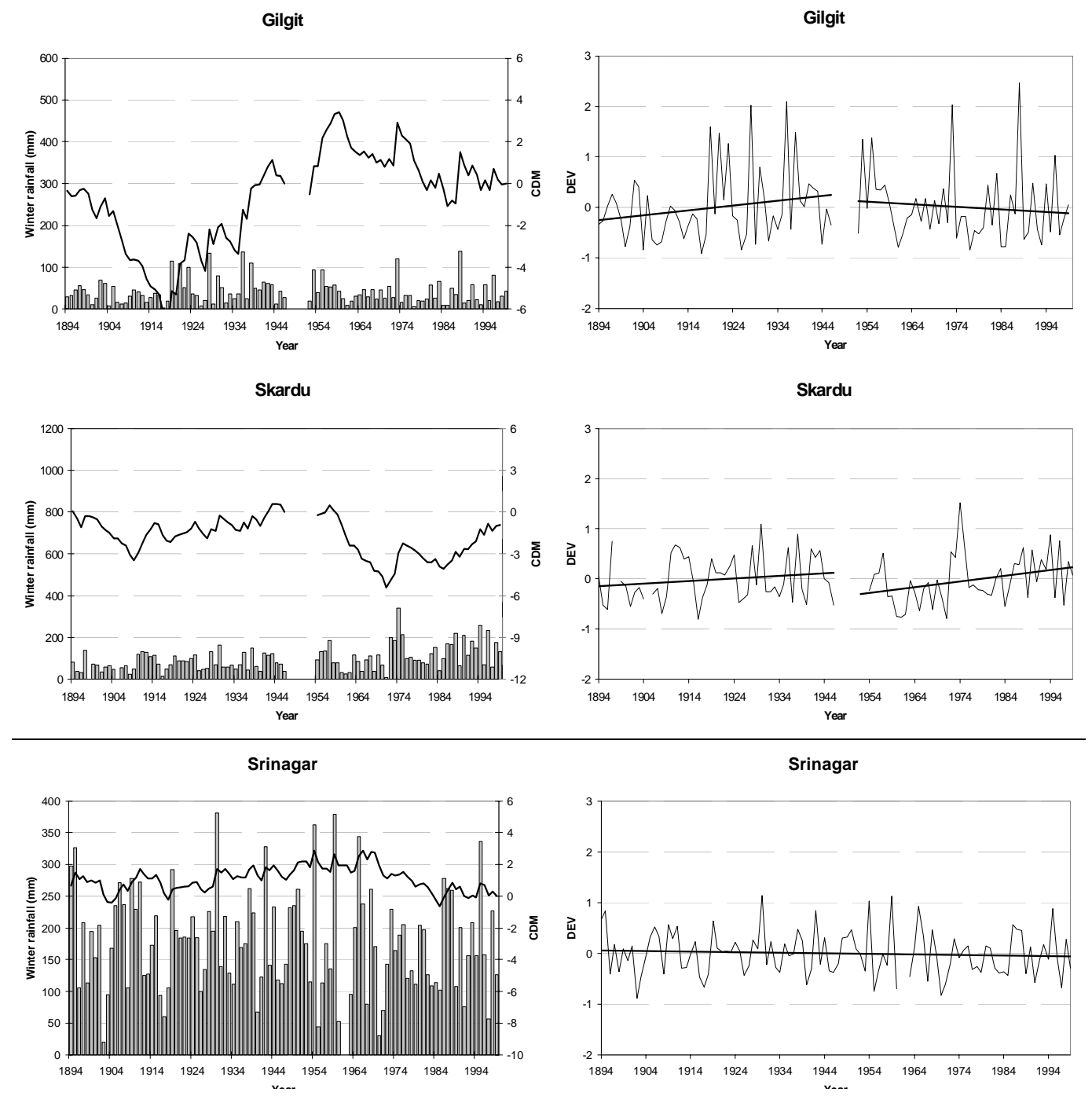

Fig.3. Trends in winter rainfall (Oct to Mar) from 1894-1999. Left hand panels show rainfall series (bars - left axis) with the cumulative departure from the mean plotted as a line (right axis). Right hand panels show the deviation from the mean winter rainfall, with a leastsquares fitted estimate of trend.

Table 4. Trend in precipitation from 1961-1999 for annual and by 3 and 6-month periods showing change per decade as a percentage of the period average (given in Table 2).

\begin{tabular}{llllllll}
\hline Station & $J-D$ & $J-M$ & $A-J$ & $J-S$ & $O-D$ & $O-M$ & $A-S$ \\
\hline Drosh & -1 & +3 & -8 & -7 & +6 & +4 & -8 \\
Gilgit & $+\mathbf{1 0}$ & +1 & +9 & +5 & +11 & +3 & +8 \\
Bunji & +13 & -7 & +10 & $+\mathbf{1 9}$ & +23 & +4 & +14 \\
Astore & +5 & +3 & -3 & $+\mathbf{1 8}$ & +16 & +5 & +3 \\
Skardu & $+\mathbf{1 4}$ & $\mathbf{+ 1 8}$ & +3 & $+\mathbf{1 7}$ & +19 & $+\mathbf{1 8}$ & +8 \\
Srinagar & +1 & +3 & -6 & +7 & -8 & +1 & +2 \\
Dir & $+\mathbf{1 1}$ & $+\mathbf{1 4}$ & +9 & +5 & +18 & $+\mathbf{1 6}$ & $+\mathbf{7}$ \\
Shahpur & $+\mathbf{1 1}$ & $\mathbf{+ 1 7}$ & +9 & +8 & +6 & $+\mathbf{1 6}$ & $+\mathbf{8}$ \\
Puran & +1 & +7 & -2 & -1 & -2 & +4 & -1 \\
Shinkiari & +1 & $+\mathbf{1 0}$ & -4 & -1 & +3 & +7 & -2
\end{tabular}

Italics show stations north of the Himalayan divide

Notes on significance of trend:

Bold $=\mathrm{P}<0.05$

Bold Italic $=\mathrm{P}<0.10$ 

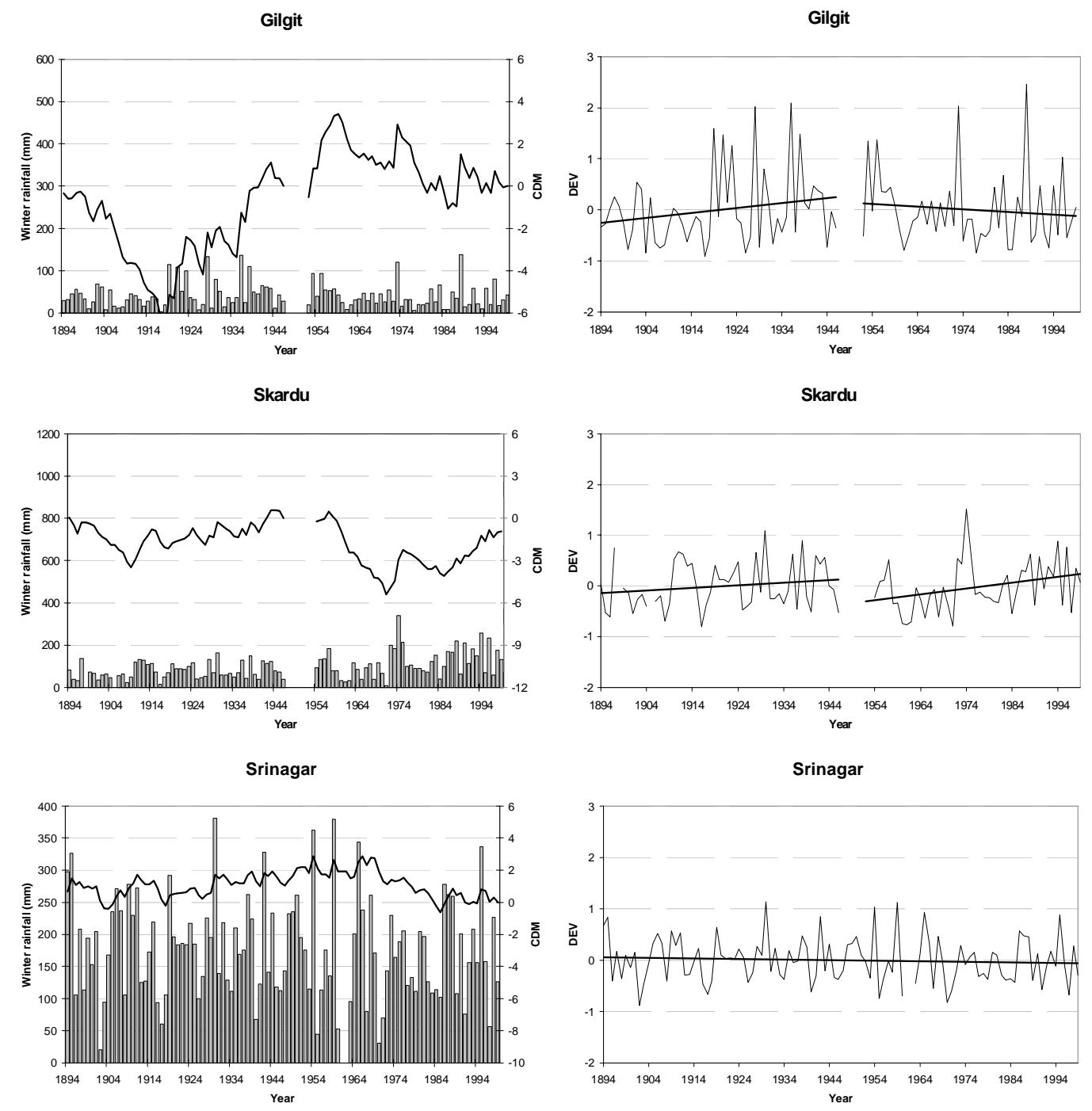

Fig.4. Trends in spring rainfall (Apr to Jun) from 1894-1999. Left hand panels show rainfall series (bars - left axis) with the cumulative departure from the mean plotted as a line (right axis). Right hand panels show the deviation from the mean spring rainfall, with a least-squares fitted estimate of trend.

inspection of monthly trends suggests that winter increases result mainly from increases during the months from December-February.

The spring (April-June) season is spatially the most varied with stations equally divided between increases and decreases and no trends are statistically significant. In contrast, summer (July-September) shows a coherent area of increasing trend. The increase is significant at Astore, Bunji and Skardu $(p<0.05)$ with decadal increases of 13,9 and $6 \mathrm{~mm}$ respectively. The trend persisted from 1961 to 1999 but intensified at these stations since 1990 (Fig. 7). Changes are mixed at southern stations where the monsoon makes a larger contribution and it is, therefore, unclear whether the significant increases further north result from more frequent incursions of the monsoon. The spring and summer records combine to give increasing trends at eight of the ten stations of which only Dir and Shahpur are significant statistically.

\section{Links to 'teleconnections'}

Winter precipitation in the UIB originates mainly from troughs of low pressure in the westerly air flow, often originating from the Mediterranean or from the Atlantic (Rao, 1981); the frequency and track of these weather systems are influenced by pressure conditions over the North Atlantic. It is likely, therefore, that rainfall changes in the Karakoram region are related at least partially to the variability of the North Atlantic Oscillation (NAO) index, usually determined by the December-March average of the normalised sea level pressure difference over the Azores and Iceland (Jones et al., 1997). Shifts in the NAO affect 
Gilgit

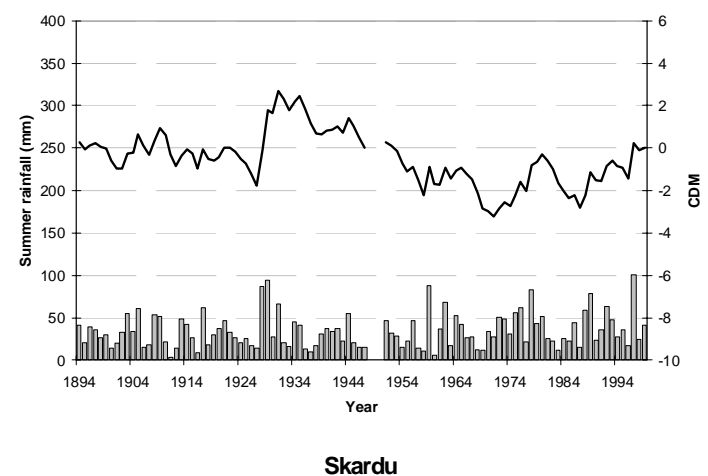

Skardu

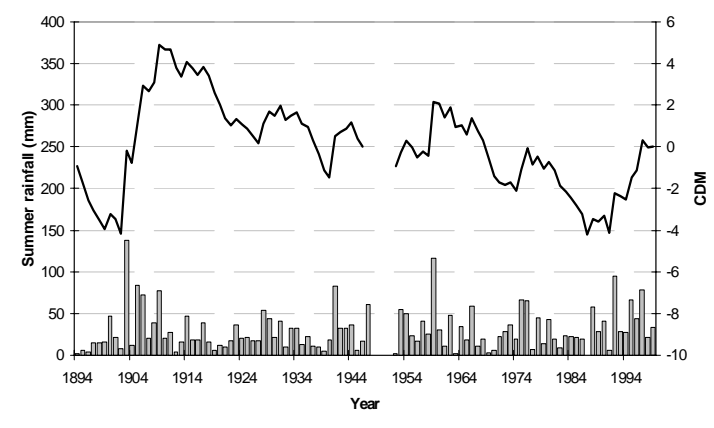

Srinagar

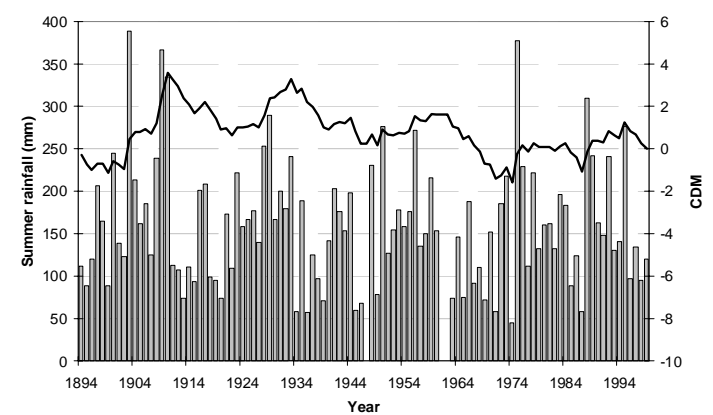

Gilgit

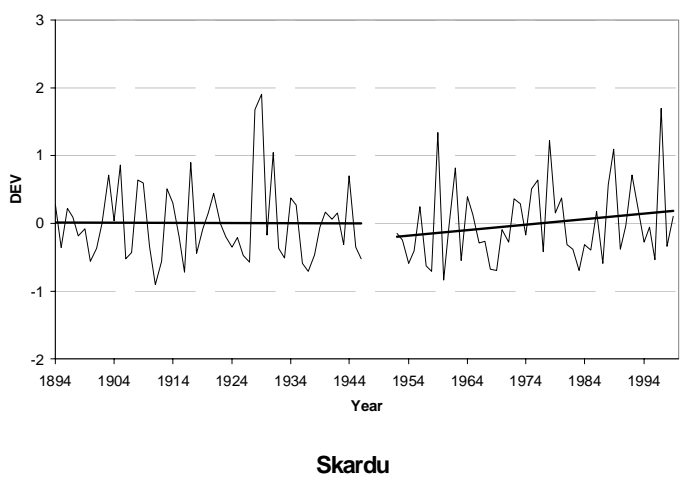

Skardu

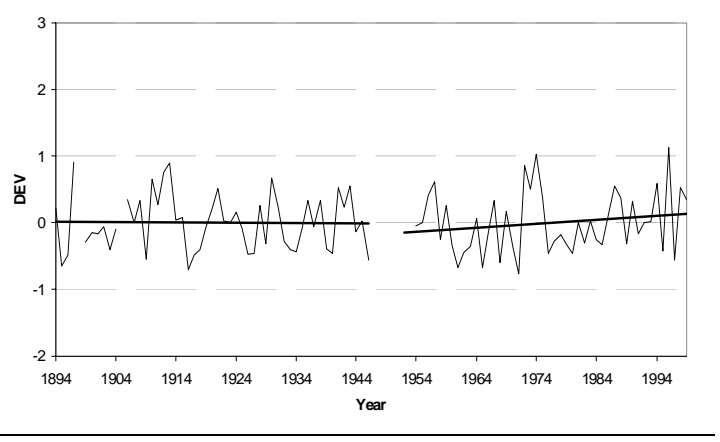

Srinagar

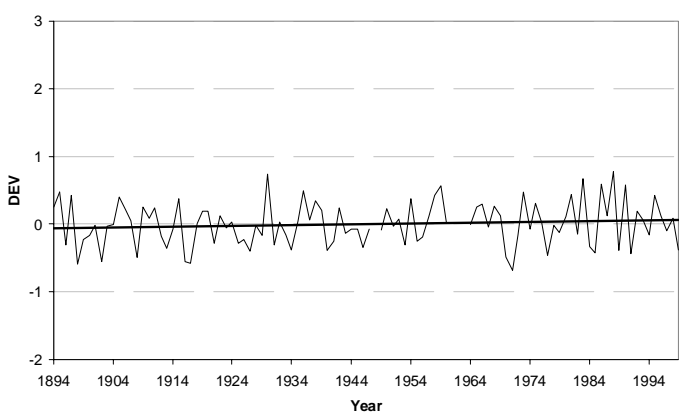

Fig.5. Trends in summer rainfall (Jul-Sep) from 1894-1999. Left hand panels show rainfall series (bars - left axis) with the cumulative departure from the mean plotted as a line (right axis). Right hand panels show the deviation from the mean summer rainfall, with a leastsquares fitted estimate of trend.

temperature and rainfall in northern Europe (Fowler and Kilsby, 2002), by changes in synoptic weather patterns, particularly the frequency and magnitude of surface westerlies (Hurrell, 1995). However, links between Atlantic weather systems and rainfall in the Karakoram region using the NAO as a predictor have not been examined previously.

In an investigation similar to that of Wilby et al. (1997), monthly rainfall amounts were correlated with the monthly average values of normalised sea level pressure difference over the Azores and Iceland (M-NAO) for the period 19611999 at the ten sites. Significant correlation statistics were obtained for some sites (Table 5). Significant positive correlation between monthly rainfall and the M-NAO was found for the winter months from November-January, particularly for northern stations. Again, the highest correlation coefficients relate to Astore.

This significant link between Atlantic weather systems and winter rainfall in the Karakoram region may be a useful predictor of summer runoff and water availability in those tributaries including the Astore and the highest gauging station on the Indus at Kharmong where summer runoff is closely correlated to rainfall in the preceding winter (OctMar) (Archer, 2003). Table 5 suggests that the strongest relationship between winter rainfall and NAO will be found by using an NAO index given by the November-January average of the normalised sea level pressure difference over the Azores and Iceland (NAO-NJ). A preliminary analysis of the correlation between NAO-NJ and winter rainfall 

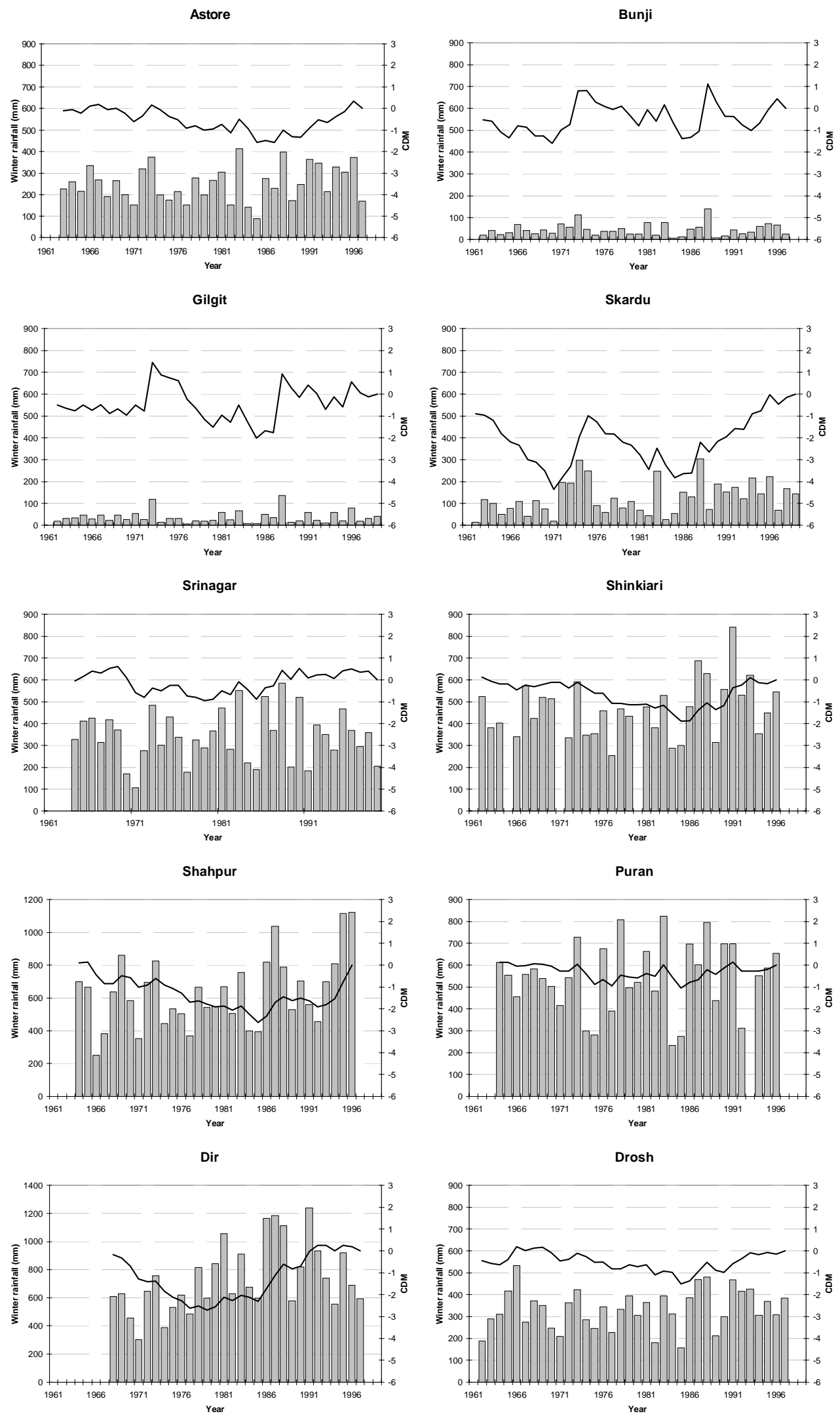

Fig.6. Trends in winter rainfall (Oct-Mar) from 1961-1999 at 10 stations. Panels show winter rainfall series (bars-left axis) with the cumulative departure from the mean plotted as a line (right axis). 

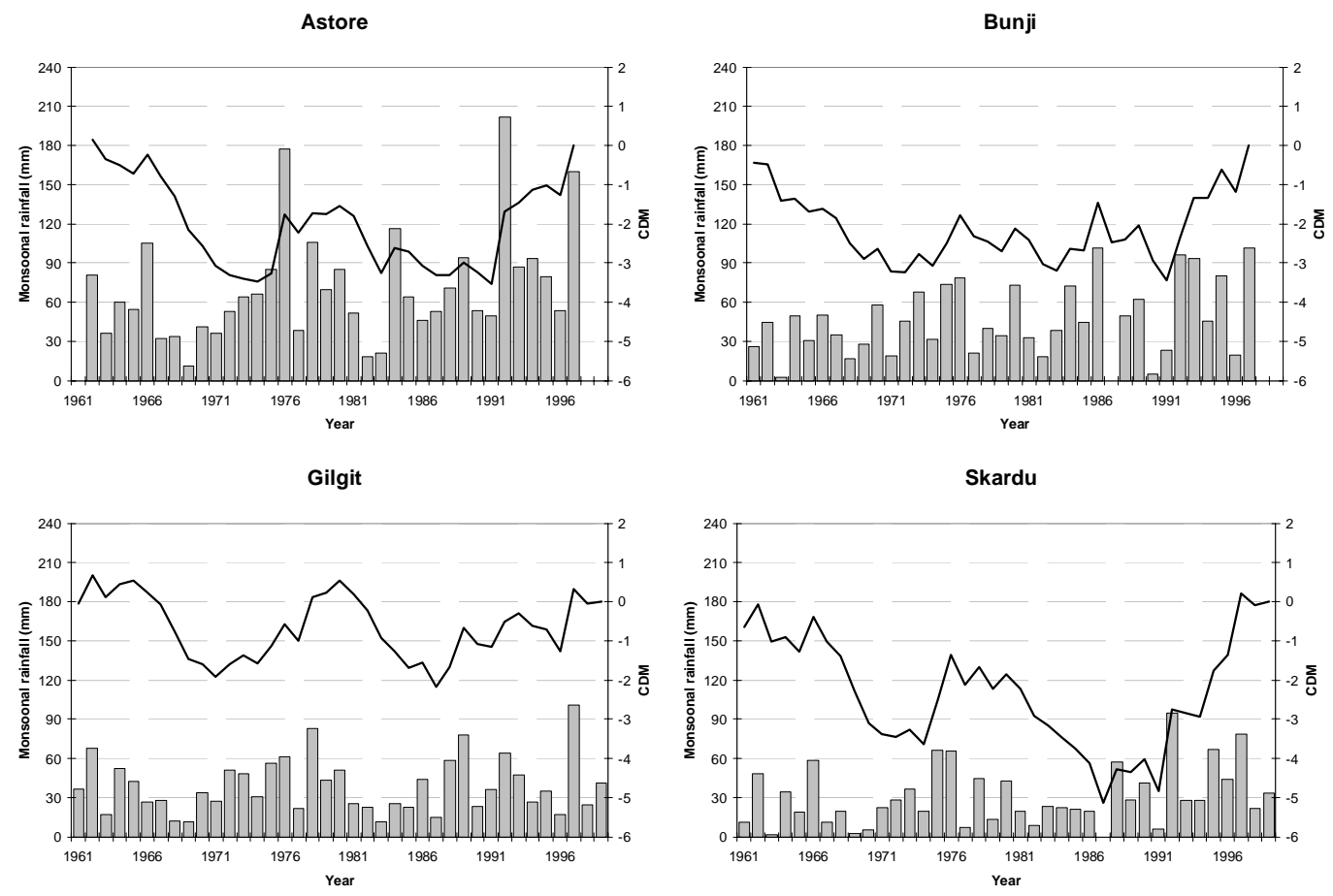

Fig.7. Trends in summer rainfall (Jul-Sep) from 1961-1999 at stations in the upper Indus basin. Panels show rainfall series (bars - left axis) with the cumulative departure from the mean plotted as a line (right axis).

Table 5. Correlation between monthly average values of normalised sea level pressure difference over the Azores and Iceland (NAO) and monthly rainfall totals at ten stations during the period 1961-99. Significant correlations at $\mathrm{p}<0.05$ are shown in bold.

\begin{tabular}{lrrrrrrrrrr}
\hline Month & Astore & Bunji & Gilgit & Skardu & Srinagar & Shinkiari & Shahpur & Puran & Dir & Drosh \\
\hline Jan & $\mathbf{0 . 3 0}$ & $\mathbf{0 . 3 2}$ & 0.10 & $\mathbf{0 . 4 1}$ & 0.08 & 0.01 & 0.04 & 0.11 & -0.04 & 0.03 \\
Feb & -0.12 & 0.18 & 0.11 & 0.28 & 0.24 & 0.18 & 0.03 & 0.02 & -0.01 & 0.07 \\
Mar & 0.06 & 0.05 & 0.03 & 0.06 & -0.18 & 0.15 & 0.28 & $\mathbf{0 . 4 7}$ & 0.27 & 0.20 \\
Apr & 0.03 & -0.29 & -0.02 & 0.01 & 0.54 & 0.21 & 0.25 & 0.27 & 0.02 & 0.13 \\
May & -0.11 & -0.26 & -0.15 & -0.17 & -0.11 & 0.28 & 0.14 & 0.17 & 0.08 & 0.01 \\
Jun & 0.01 & -0.22 & -0.44 & -0.15 & -0.44 & 0.26 & 0.04 & 0.14 & -0.22 & -0.19 \\
Jul & -0.21 & 0.11 & 0.01 & 0.04 & 0.15 & 0.00 & -0.11 & -0.14 & -0.44 & -0.08 \\
Aug & 0.17 & -0.37 & -0.08 & -0.07 & 0.18 & -0.06 & -0.05 & -0.11 & -0.05 & -0.09 \\
Sep & 0.03 & -0.14 & -0.09 & -0.17 & -0.17 & 0.03 & -0.28 & -0.05 & -0.10 & -0.30 \\
Oct & -0.10 & -0.03 & -0.01 & -0.03 & 0.12 & -0.09 & 0.01 & -0.04 & -0.21 & -0.18 \\
Nov & 0.38 & 0.01 & 0.02 & 0.01 & -0.04 & 0.29 & 0.24 & 0.02 & 0.32 & 0.34 \\
Dec & 0.34 & -0.19 & 0.00 & -0.28 & -0.04 & 0.29 & 0.32 & 0.27 & 0.38 & 0.23 \\
\hline
\end{tabular}

suggests that, for summer runoff prediction, this may be an important explanatory variable (Table 6).

However, the high negative correlation between M-NAO and rainfall at stations in some summer months is rather more surprising and suggests that westerly weather also influences the Karakoram region in summer.

Several previous studies have linked summer monsoon rainfall in India to the El Niño Southern Oscillation (Parthasarathy et al., 1991; Barnett et al., 1991); more recently, the Southern Oscillation Index, itself highly correlated to ENSO, has been associated with summer rainfall in Nepal (Shrestha et al., 2000). Although there was little evidence of a connection between summer weather in the Atlantic/Mediterranean and the Indian Monsoon, idealised modelling by Rodwell and Hoskins (1996) linked the settled summer climate of the Mediterranean with the period of the Asian summer monsoon. More recently, Raicich et al. (2003) investigated the strong teleconnection 
Table 6. Correlation between a November to January average NAO pressure index and winter (Oct-Mar) and Dec-Feb rainfall totals at ten stations during the period 1961-99. Significant correlations at $\mathrm{p}<0.05$ are shown in bold.

\begin{tabular}{llc}
\hline & $\begin{array}{l}\text { Winter (Oct-Mar) } \\
\text { rainfall }\end{array}$ & $\begin{array}{l}\text { Dec-Feb } \\
\text { rainfall }\end{array}$ \\
\hline Skardu & $\mathbf{0 . 3 0}$ & 0.24 \\
Gilgit & 0.02 & 0.04 \\
Astore & 0.19 & $\mathbf{0 . 4 3}$ \\
Bunji & 0.12 & $\mathbf{0 . 3 6}$ \\
Puran & 0.03 & 0.08 \\
Shinkiari & 0.16 & 0.12 \\
Shahpur & 0.09 & -0.06 \\
Dir & 0.25 & 0.10 \\
Drosh & 0.21 & 0.27 \\
Srinagar & 0.23 & 0.21 \\
\hline
\end{tabular}

between the Indian monsoon and rainfall in the Sahel region of Africa and postulated the meteorological dynamics of the Mediterranean area as an explanation. In summer, a Mediterranean pressure index is found to be strongly anticorrelated with the Indian monsoon $(\mathrm{C}=-0.68)$ (Raicich et al., 2003). The strong negative correlation found in the present study between $\mathrm{M}-\mathrm{NAO}$ and rainfall in months coinciding with the Indian monsoon (Jun-Sep) at some Karakoram stations and the negative correlation between summer precipitation at stations north and south of the Himalayan divide, suggests that, in summer, there is an interplay of weather from westerly and monsoon sources on the climate of the region.

\section{Discussion}

Changes in the amount and seasonal distribution of precipitation have potentially serious implications for glaciological and hydrological regimes and so for management of water resources in the entire Indus basin. The focus of analysis of precipitation time series is on the accumulation of snow during the winter months and subsequent summer runoff.

Archer (2003) showed that winter (Oct-Mar) precipitation measured at a single station at low elevation is significantly correlated with summer (Jul-Sep) runoff for many upper Indus tributaries, suggesting a possibility of forecasting with a long lead time. Correlation coefficients of over 0.7 occur between winter precipitation at Astore and summer runoff for the upper Indus at Kharmong (basin area $72500 \mathrm{~km}^{2}$ ) and for the River Astore at Doyien $\left(3750 \mathrm{~km}^{2}\right)$. The strong spatial correlation of winter precipitation demonstrated here explains why a single rainfall station can be so effective in predicting runoff.

On these catchments, any trend in winter precipitation arising from anthropogenic or other sources of climate change will, therefore, be reflected directly in summer runoff. Wigley and Jones (1985) suggested that changes in precipitation have an amplified effect on runoff. Direct assessment of the effect of increased precipitation can be made for specific basins using regressions between winter rainfall and summer runoff. However, the percentage increases in predicted runoff are less than those for rainfall; a $10 \%$ increase in precipitation at Astore gives a $5 \%$ increase in runoff at Doyien and a 4\% increase at Kharmong.

In addition, both the strong spatial correlation of precipitation between stations separated by high mountain barriers and the correlation between rainfall and runoff, suggest that rainfall measured at low-lying stations is also correlated with precipitation at higher, more glaciologically active, altitudes. Decreased net accumulation on glaciers would lead ultimately (but with different lag times dependent on the size and characteristics of the glacier) to glacier retreat and a decreased contribution to runoff from glacier melt.

Notwithstanding the above observations, precipitation data in the region provide no significant statistical evidence of long-term trend, either increasing or decreasing, in any of the seasonal or annual series investigated. However, since 1961, there is an upward trend in winter rainfall at all stations investigated in the region, both to the north and south of the Himalayan divide, showing significant correlation of winter precipitation across the region. These trends are significant, statistically $(p<0.05)$ at the northern station of Skardu and southern stations of Shahpur and Dir and concur with predictions by Global Climate Models of an increase in winter precipitation over middle and high latitudes of the Northern Hemisphere.

The overall impact of climate change on glacial balance and hydrological regime requires the joint consideration of changes in both precipitation and energy budget. The impacts of changes in temperature as an index of energy input are considered in Archer (2001); whilst significant changes are observed in some seasons at some locations, these are not as dramatic as the increases noted by Shrestha et al. (1999) for the Nepalese Himalaya. However, together, the differences in precipitation and temperature change between the Himalayas and the trans-Himalayan ranges go some way to explaining difference in glaciological responses between the two areas illustrated by Hasnain (1999) for the Himalayas and by Hewitt (1998) for the Karakoram.

The strong spatial correlation of winter precipitation and trend in winter precipitation across the region may be explained by reference to teleconnections. Statistically 
significant correlations were obtained between winter precipitation and a monthly index of the NAO, particularly during the period from November to January. The highest correlations were found at Astore; this is of practical importance as winter precipitation provides a strong predictor of summer runoff and, thus, of water availability in the UIB.

However, the link between Atlantic weather systems and summer rainfall at stations both north and south of the Himalayan divide is perhaps more surprising. Summer rainfall in the Karakoram region was thought to derive mainly from the monsoon. However, the negative correlation between summer rainfall at stations north and south of the divide and the significant correlation with the NAO suggests that, in summer, the climate of the region is the product of interplay of weather from both monsoonal and westerly sources. North of the Himalayan divide, since 1961, there has been a statistically significant $(p<0.05)$ increase in rainfall at the three stations of Astore, Bunji and Skardu. It is unclear, however, whether this results from a stronger westerly influence on summer weather, or to more frequent incursions of the monsoon from the south.

\section{Conclusions}

1. In spite of the purported variability of mountain rainfall, winter precipitation is highly correlated spatially across the upper Indus basin, north and south of the Himalayan divide. The analysis supports the view that seasonal forecasts of summer flow in the Indus can be made from standard meteorological measurements at valley stations.

2. Over the last century, there is no statistically significant long-term trend in annual or seasonal precipitation time series. This result supports Khan's (2001) analysis. However, separate consideration of seasonal datasets has revealed patterns of change not evident using the decomposition method of Khan (2001). Contrary to Miehe's (1992) perception of a decrease in winter precipitation in the Karakoram, there is evidence of an upward trend across the region since 1961, statistically significant $(p<0.05)$ at Skardu, Shahpur and Dir. It may be that temperature changes will explain these observed phenomena.

3. Preliminary analysis has identified significant correlation between the winter North Atlantic Oscillation and winter precipitation in the Karakoram.

4. Negative correlation between M-NAO and summer rainfall at some Karakoram stations and the negative correlation between summer precipitation at stations north and south of the Himalayan divide, suggests that the Karakoram and Hindu Kush mountains occupy a pivotal position between the monsoon and the influence of westerly airflow. North of the Himalayan divide, there has been a statistically significant $(p<0.05)$ increase in summer rainfall since 1961. However, it is unclear whether this results from increased incursion by the monsoon or a stronger westerly flow.

5. Whilst teleconnections are of considerable theoretical interest, the levels of correlation so far observed are of limited practical value for water resources management. Although a more comprehensive analysis of links to a range of global climatic variables is needed, much more is to be gained at this stage by developing the links between observed climate and runoff in the River Indus.

\section{Acknowledgments}

The work was initiated whilst the first author was a volunteer with Voluntary Service Overseas (VSO) and employed by the German Agency for Technical Development (GTZ). The author thanks colleagues of both agencies for the opportunity and for their support. Particular thanks are due to GTZ counterpart Juan Jose Victoria. Support was also provided by officials of WAPDA and the Pakistan Meteorological Department and the help of the PMD Director, Shaukat Ali Awan, is acknowledged for supply of data and helpful discussion. The authors also thank Chris Kilsby for useful comments.

\section{References}

Archer, D.R., 2001. The climate and hydrology of northern Pakistan with respect to the assessment of flood risk and hydropower schemes. Unpublished report. GTZ/WAPDA/VSO, Lahore.

Archer, D.R., 2002. Flood risk evaluation in the Karakoram Himalaya: implications of non-homogeneity and nonstationarity. Proc. Eighth National Hydrology Symposium, British Hydrological Society, Sept. 2002. 7-12.

Archer, D.R., 2003. Contrasting hydrological regimes in the Indus Basin. J. Hydrol., 274, 198-210.

Archer, D.R., in press. Hydrological implications of spatial and altitudinal variation in temperature in the upper Indus basin. Nordic Hydrol., 33.

Barnett, T.P., Dümenil, L., Schlese, U., Roeckner, E. and Latif, M., 1991. The Asian snow cover-monsoon-ENSO connection. In: Teleconnections linking worldwide climate anomalies, M.H. Glantz, R.W. Katz and N. Nicholls, (Eds.). Cambridge University Press, Cambridge, UK. 191-225.

Borgaonkar, H.P., Pant, G.B. and Rupa Kumar, K., 1996. Ringwidth variations in Cedrus deodora and its climatic response over the western Himalaya. Int. J. Climatol., 16, 1409-1422.

Chang, C.C., 1981. A contrasting study of the rainfall anomalies between central Tibet and central India during the summer monsoon season 1979. Bull. Amer. Meteorol. Soc., 62, 20-22. 
Cramer, T., 1993. Climatological investigation in Bagrot Valley, In: Cultural Area Karakoram Newsletter. 3, 19-22, Tubingen, Germany.

De Scally, F.A., 1994. Relative importance of snow accumulation and monsoon rainfall for estimating the annual runoff, Jhelum basin, Pakistan. Hydrolog. Sci. J., 39, 199-216.

Fowler, H.J. and Kilsby, C.G., 2002. Precipitation and the North Atlantic Oscillation: A study of climatic variability in Northern England. Int. J. Climatol., 22, 843-866.

Hahn, D.G. and Shukla, J., 1976. An apparent relationship between the Eurasian snow cover and Indian monsoon rainfall. J. Atmos. Sci., 33, 2461-2462.

Hasnain, S.I., 1999. Report of Working Group on Himalayan Glaciology, International Commission on Snow and Ice.

Hewitt, K., 1982. Natural dams and outburst floods in the Karakoram Himalaya. IAHS Publication no. 138, 259-269.

Hewitt, K., 1998. Glaciers receive a surge of attention in the Karakoram Himalaya. EOS Transactions, American Geophysical Union, 79/8, February 24, 104-105.

Hewitt, K., 2001. Upper Indus glaciers. Hazards of melting as an option. Dawn, 20 May

Hurrell, J.W., 1995. Decadal trends in the North Atlantic Oscillation: regional temperatures and precipitation. Science, 269, 676-679.

Inter-governmental Panel on Climate Change (IPCC). 2001. Third Assessment Report Climate Change. Cambridge University Press, UK.

Jacobsen, J-P., 1993. Climate records from Northern Pakistan (Yasin Valley). In: Cultural Area Karakoram Newsletter 3, 2225, Tubingen, Germany,

Jones, P.D., Jónsson, T. and Wheeler, D., 1997. Extension to the North Atlantic Oscillation using early instrumental pressure observations from Gibraltar and south-west Iceland. Int. J. Climatol. 17, 1433-1450.

Khan, A. R., 2001. Analysis of hydro-meteorological time series: Searching evidence for climatic change in the Upper Indus Basin. Lahore, Pakistan: International Water Management Institute. (IWMI Working Paper 23)

Mastny, L., 2000. Melting of earth's ice cover reaches new high. World Watch Institute, Washington D.C. USA. (www.worldwatch.org).

Miehe, G., 1992. Recent climatic change in the Karakoram as indicated by vegetation features and geomorphological processes. In: Cultural Area Karakoram Newsletter 2.

Parthasarathy, B., Kumar, K.R. and Munot, A.A., 1991. Evidence of secular variations in Indian monsoon rainfall circulation relationships. J. Climate, 4, 927-938.
Pearce, F., 2002. Meltdown! New Scientist, 2367, 45-48

Raicich, F., Pinardi, N. and Navarra, A., 2003. Teleconnections between Indian monsoon and Sahel rainfall and the Mediterranean. Int. J. Climatol., 23, 173-186.

Rao, Y.P., 1981. The Climate of the Indian Sub-continent. In: World Survey of Climatology, Vol. 9, Climates of Southern and western Asia. Elsevier, Amsterdam, The Netherlands.

Rodwell, M.J. and Hoskins, B.J., 1996. Monsoons and the dynamics of deserts, Quart. J. Roy. Meteorol. Soc., 122, 13851404.

Shrestha, A.B., Wake, C.P., Dibb, J.E. and Mayweski, P.A., 2000. Precipitation fluctuations in the Nepal Himalaya and its vicinity and relationship with some large scale climatological parameters. Int. J. Climatol. 20, 317-327.

Singh, P., Ramashastri, K.S. and Kumar, N., 1995. Topographic influences on precipitation distribution in different ranges of the Western Himalayas. Nordic Hydrol., 26, 259-284.

Singh, R.B. and Sen Roy, S., 2002. Climate variability and hydrological extremes in a Himalayan catchment. ERB and Northern European FRIEND Project 5 Conf., Slovakia.

Wake, C.P., 1987. Snow accumulation studies in the central Karakoram. Proc. Eastern Snow Conf. 44 $4^{\text {th }}$ Annual Meeting Fredericton, Canada. 19-33.

Wake, C.P., 1989. Glaciochemical investigations as a tool to determine the spatial variation of snow accumulation in the Central Karakoram, Northern Pakistan Ann. Glaciology, 13, 279-284.

Wigley, T.M.L. and Jones, P.D., 1985. Influences of precipitation and direct $\mathrm{CO}$ effects on streamflow. Nature, 314, 149-152.

Wilby, R.L., O'Hare, G. and Barnsley, N., 1997. The North Atlantic Oscillation and British Isles climate variability, 1865-1996. Weather, 52, 266-276.

World Glacier Monitoring Service (WGMS), 2000. Glacier mass balance data 1998/99. (www.geo.unizh.ch)

World Meteorological Organisation. 1970. Guide to Meteorological Practices, $2^{\text {nd }}$ Ed. WMO No 168, Tech Paper 82, Geneva, Switzerland.

Yamada, T. and Sharma, C.K., 1993. Glacier lakes and outburst floods in the Nepal Himalaya. In: Snow and Glacier Hydrology (Proceedings of a Kathmandu Symposium). IAHS publication no. 218, 319-330.

Yang, S., 1996. Enso-Snow-Monsoon associations and seasonalinterannual predictions, Int. J. Climatol., 16, 125-134.

Ye, H. and Bao, Z., 2001. Lagged teleconnections between snow depth in northern Eurasia, rainfall in southeast Asia and seasurface temperatures over the tropical Pacific Ocean. Int. J. Climatol., 21, 1601-1621. 